\title{
Meningkatkan Pelayanan JNE di Batas Negeri
}

\author{
Sri Octaviana ${ }^{1}$ Hendra Laksamana ${ }^{2}$ Adi Aspian Nur ${ }^{3}$ \\ ${ }^{1}$ Fakultas Ekonomi, Jurusan Ekonomi Pembangunan, Universitas Kaltara. Jln. \\ Sengkawit RT. XVI Bulungan, Provinsi Kalimantan Utara 73212 \\ ${ }^{2}$ Fakultas Ekonomi, Jurusan Ekonomi Pembangunan, Universitas Kaltara. Jln. \\ Sengkawit RT. XVI Bulungan, Provinsi Kalimantan Utara 73212 \\ ${ }^{3}$ Fakultas Ekonomi, Jurusan Ekonomi Pembangunan, Universitas Kaltara. Jln. \\ Sengkawit RT. XVI Bulungan, Provinsi Kalimantan Utara 73212 \\ E-mail : adiaspiannur22@gmail.com, Telp : +6281351876400
}

\begin{abstract}
ABSTRAK
Dalam hal pemesanan barang yang diinginkan konsumen adalah barang datang tepat waktu atau tidak terlalu lama menunggu pesanan. Maka dari itu dibutuhkan perusahaan jasa yang dapat melakukan hal tersebut, satu diantaranya adalah JNE.

PT Jalur Nugraha Ekakurir (JNE) merupakan perusahaan terbesar yang bergerak pada industri ekspedisi di Indonesia. Dengan network yang dapat mencapai seluruh kabupaten dan kota di Indonesia. JNE menjadi perusahaan logistik dengan network yang sangat luas secara nasional.

Untuk mempermudah dalam analisis, maka kami membatasi pembahasan pada JNE Tanjung Selor. Permasalahan yang terjadi pada JNE Tanjung Selor adalah permasalahan internal dan eksternal perusahaan, permasalahan pelayanan yang diberikan oleh JNE Tanjung Selor, serta permasalahan terkait dengan keterlambatan pengiriman barang. Dan solusi yang dapat kami usulkan untuk permasalahan tersebut adalah membuat fasilitas untuk nomor antrian bagi konsumen JNE Tanjung Selor serta penambahan kursi, penambahan fiture baru di aplikasi My JNE, serta penerapan JNE Loyalty Card (JLC) di Tanjung Selor.
\end{abstract}

Kata Kunci : Pemesanan Barang, JNE 


\section{BAB I \\ PENDAHULUAN}

\section{A. Latar Belakang}

PT TIKI Jalur Nugraha Ekakurir (PT TIKI JNE) merupakan salah satu perusahaan terbesar yang bergerak pada industri ekspedisi di Indonesia. Dengan network yang mencapai tingkat kabupaten di seluruh Indonesia, JNE menjadi perusahaan logistik dengan network yang sangat luas secara nasional. JNE juga bergerak di bidang freight yang menjadikan cakupan bisnisnya tidak hanya berfokus pada industri nasional meskipun pendapatan perusahaan secara mayoritas masih bersumber pada bisnis nasionalnya [1]

PT Tiki Jalur Nugraha Ekakurir merupakan perusahaan yang berfokus pada bisnis express, logistic, dan freight. Pada tahun 1990, PT Tiki Jalur Nugraha Ekakurir (PT. JNE) memulai usahanya dengan fokus pada bisnis express dan logistik kepabeanan (impor) barang maupun dokumen. Pada tahun 2000, PT JNE menjadi perusahaan sendiri dan berpisah dari TIKI. Kini JNE telah menjadi perusahaan logistik yang besar di Indonesia dengan jangkauannya ke seluruh Indonesia hingga tingkat Kabupaten. Produk JNE terus mengalami perkembangan, mulai dari penambahan layanan seperti YES (Yakin Esok Sampai), hingga penambahan jasa seperti PESONA (Pesanan Oleh-Oleh Nusantara), Jesika (Jemput ASI Seketika), dan sebagainya [1]

JNE memiliki visi yang merupakan tujuan utama perusahaan di masa yang akan datang "Untuk menjadi perusahaan rantai pasok global terdepan di dunia". Dalam upaya mencapai visi, JNE memiliki misi yaitu memberi pengalaman terbaik kepada pelanggan secara konsisten, melayani segenap lapisan masyarakat Indonesia baik perumahan maupun perkantoran dan industri melalui jaringan layanan pengiriman ekspres, memadukan efektivitas, efisiensi dan fleksibilitas jasa yang prima untuk menjadikan JNE pilihan utama dalam pengiriman dokumen, paket dan kargo peka waktu di Indonesia, dan menjadi sebuah perusahaan jasa ekspres nasional berstandar layanan internasional [1]

Untuk memudahkan analisis permasalahan, kami memilih JNE cabang Tanjung Selor sebagai sample dalam proposal ini. Menurut Hartono selaku Pimpinan di JNE Tanjung Selor "Sejarah JNE dimulai pada tahun 2006 dengan sistem otonum yaitu pembagian persentase antara pemilik CV dengan pihak JNE. Dengan persentase pemilik CV mendapatkan 25\% dari keuntungan dan sisanya diberikan kepada JNE". Jumlah pekerja saat ini sebanyak 10 orang karyawan yang bekerja di JNE Tanjung Selor. Dengan fasilitas pengiriman berupa motor dan mobil. Hingga saat ini JNE Tanjung Selor menjadi zona B setelah Tarakan. JNE di Tanjung Selor berada di Skip I Tanjung Selor, Kabupaten Bulungan, Kalimantan Utara 77214 [2]

Hasil wawancara diperoleh permasalahan yaitu :

1. Permasalahan dalam internal JNE adalah miss komunikasi antara konsumen dan pengirim barang yang menyebabkan keterlambatan barang yang sampai kepada pengirim. Contohnya pembelian barang melalui market place yang penjualnya ada di Bekasi, karena pembeli sudah 
mentransfer uang pembeli mengira pada saat itu juga barang sudah dikirim tetapi belum;

2. Sering terjadi alamat yang diberikan oleh penerima salah serta nomor telpon tidak jelas atau tidak terhubung;

3. Pesaing dari perusahaan lain yang sangat berdampak terhadap JNE Tanjung Selor.

4. Kurang nyamannya ruang tunggu di kantor JNE Tanjung Selor (Versi Konsumen)

5. Target pengiriman yang tidak tepat waktu (Versi Konsumen)

6. Pelayanan yang kurang baik (Versi Konsumen)

Pelayanan merupakan menolong menyediakan segala apa yang diperlukan orang lain seperti tamu atau pembeli [3]

Berdasarkan permasalahan yang dikemukakan baik dari pihak JNE maupun dari konsumen maka peneliti menyimpulkan bahwa adanya pelayanan yang tidak sesuai dengan standar pelayanan yang telah ditetapkan oleh JNE dan juga kesalahan dari konsumen sendiri yang menyebabkan barang yang akan diterima lama sampai .

Permasalahan ini apabila dibiarkan secara terus menurus, maka konsumen JNE akan memilih competitor lain. Dan dengan hal itu maka JNE akan mengalami kerugian.

Hasil penelitian [4] diperoleh bahwa kualitas layanan yang terdiri dari kehandalan, kepastian, kenyataan, empati, dan daya tanggap, memiliki pengaruh signifikan terhadap kepuasan pelanggan. Variabel yang memberikan pengaruh besar adalah variabel empati.

\section{B. RUMUSAN MASALAH}

Berdasarkan latar belakang yang dikemukan maka rumusan masalah yang dapat dibuat adalah:

1. Apa saja permasalahan internal dan eksternal JNE Tanjung Selor?

2. Bagaimana bentuk pelayanan yang diberikan oleh JNE Tanjung Selor kepada konsumen?

3. Bagaimana cara menghadapi pesaing JNE Tanjung Selor dibidang yang sama?

\section{TUJUAN}

Dari rumusan masalah diatas, dapat disimpulkan bahwa tujuan proposal ini dibuat adalah:

1. Mengetahui apa saja permasalahan yang dihadapi JNE Tanjung Selor baik dari internal maupun eksternal.

2. Mengetahui bagaimana pelayanan yang harus diberikan oleh JNE Tanjung Selor kepada pelanggan.

3. Mengetahui cara agar bisa tetap unggul dari kompetitor lain. 


\section{BAB II PEMBAHASAN}

. Pada tahun 1990, PT Tiki Jalur Nugraha Ekakurir (PT. JNE) memulai usahanya dengan fokus pada bisnis express dan logistik kepabeanan (impor) barang maupun dokumen. Pada tahun 2000, PT JNE menjadi perusahaan sendiri dan berpisah dari TIKI. Kini JNE telah menjadi perusahaan logistik yang besar di Indonesia dengan jangkauannya ke seluruh Indonesia hingga tingkat Kabupaten.

PT Tiki Jalur Nugraha Ekakurir (PT. JNE) juga memiliki cabang di Kalimantan Utara khususnya di daerah Tanjung Selor. Menurut wawancara dengan kepala JNE Tanjung Selor, Bapak Rudi Hartono, beliau mengatakan bahwa JNE cabang Tanjung Selor ini berdiri pada tahun 2006. Degan menggunakan sistem otonum yaitu pembagian persentase antara pemilik CV dengan pihak JNE. Dengan persentase pemilik CV mendapatkan 25\% dari keuntungan dan sisanya diberikan kepada JNE. Alamat JNE di Tanjung Selor berada di Skip I Tanjung Selor, Kabupaten Bulungan, Kalimantan Utara. Hingga saat ini karyawan yang bekerja di JNE Tanjung Selor berjumlah 10 orang. Tetapi dengan jumlah karyawan yang berjumlah 10 orang ini belum efektif dan efesien untuk melayani konsumen. Sehingga harus ada penambahan karyawan JNE Tanjung Selor.

Di dalam setiap usaha yang dibangun baik oleh perorangan maupun kelompok pasti memiliki masalah yang dihadapi, yang apabila dibiarkan maka akan berdampak pada perusahaan tersebut.

Berdasarkan hasil wawancara dengan kepala JNE Tanjung Selor, Bapak Rudi Hartono dapat disimpulkan permasalahan yang terjadi di JNE Tanjung Selor adalah sering terjadi miss komunikasi antara pengirim dan penerima yang menyebabkan keterlambatan barang sampai kepada penerima. Ini juga menjadi keluhan pelanggan karena keterlambatan barang pada saat pengiriman. Contohnya pembelian barang melalui market place yang penjualnya ada di Bekasi, karena pembeli sudah mentransfer uang, pembeli mengira pada saat itu juga barang sudah dikirim tetapi nyatanya barang belum dikirim oleh saler atau pengirimnya atau bisa juga dikatakan keterlambatan pengiriman barang oleh pengirim. Karena hal tersebut, sering terjadi keterlambatan barang yang sampai ke tangan konsumen, sehingga pelanggan komplain dan menyalahkan pihak JNE.

Selain karena miss komunikasi yang terjadi, salah satu penyebab keterlambatan barang sampai karena di Tanjung Selor masuk zona B, setelah zona A yaitu Tarakan. Belum lagi dengan barang yang harus diantar di luar kota, misalnya daerah Mangkupadi yang masuk di zona $\mathrm{C}$ tetapi barang akan dikirim dalam jangka waktu 1 minggu harus selesai. Keterlambatan barang yang sampai juga bisa dikarenakan karena overload bagasi pesawat, yang menyebabkan barang tertahan sehingga tidak sesuai estimasi waktu awal. Selain itu juga keterlambatan barang yang sampai dikarenakan alamat penerima yang tidak jelas, dan juga nomor telepon yang diberikan tidak bisa dihubungi.

Kualitas pelayanan tergantung pada interaksi manusia dalam pelayanan yang dihadapi dan hasil dari kualitas pelayanan berhubungan dengan proses interaktif antara penyedia jasa dan penerima jasa. Mengenai kualitas pada industri 
jasa salah satunya adalah communication, yaitu komunikasi atau hubungan antara penerima jasa dengan pemberi jasa. Telah jelas bahwa komunikasi adalah hal penting dalam perusahaan jasa, apabila tidak dikomunikasikan dengan baik pasti akan sering terjadi kesalahpahaman yang apabila diteruskan maka lama kelamaan akan mengurangi pelanggan JNE Tanjung Selor [5]

Peningkatan biaya transportasi udara juga menjadi salah satu keluhan pelanggan yang juga berdampak pada kenaikan harga pengiriman barang oleh JNE. Jakarta, CNN Indonesia, Ketua Umum Indonesia National Air Carrier Association (INACA) Akshara Danadiputra mengisyaratkan pelemahan rupiah terhadap dolar AS menjadi biang keladi maskapai penerbangan menaikkan harga tiket pesawat. Menurut dia, pelemahan rupiah tidak sebanding harga tiket pesawat domestik. "Dari 2016 sampai 2018 kurs kita sudah melemah sekitar $170 \%$. Sedangkan maskapai penerbangan dari April 2016 tidak ada kenaikan," tutur Akshara dalam jumpa pers di Jakarta, Minggu (13/1). Padahal, beberapa harga komponen pokok dari penerbangan meroket. Misalnya, harga bahan bakar (avtur) yang sudah naik $165 \%$ sejak 2016 lalu. Belum lagi, pajak pertambahan nilai (PPN) yang ditanggung penerbangan domestik [6]

Perusahaan jasa pengiriman JNE menaikkan tarif pengiriman dari Jabodetabek ke seluruh Indonesia 10\%-40\%. Kebijakan ini berlaku mulai tanggal 15 Januari 2019. Presiden Direktur Mohamad Feriadi mengatakan tarif kargo angkutan udara yang naik signifikan menjadi alasan perusahaan mengambil keputusan ini. Biaya kargo yang terus naik memaksa perusahaan mengambil kebijakan ini. "Ini yang sangat terasa sebetulnya adalah beban biaya kita yang pengiriman udara. Tarif secara keseluruhan naik," katanya kepada detikFinance saat dihubungi, Senin (14/1/2019). "Memang tarif surat muatan udara mengalami peningkatan yang signifikan, sehingga kalau kita tidak melakukan penyesuaian tentu ini akan menjadi beban yang sangat berat buat kami," tambahnya [6]

Kenaikan harga pengiriman barang atau yang biasa disebut dengan ongkir telah sangat jelas penyebabnya karena kenaikan harga bahan bakar (avtur) serta Pajak Pertambahan Nilai (PPN). Agar pelanggan tidak beralih dengan perusahaan lain tergantung bagaimana pelayanan yang diberikan.

Berdasarkan hasil wawancara dengan kepala JNE Tanjung Selor Bapak Rudi Hartono, mengatakan bahwa ada keluhan atau permasalahan pelanggan yang dialami saat berlangganan tetapi bisa diselesaikan. Dan juga pada saat kami melakukan wawancara dengan pelanggan, ada keluhan mengenai pelayanan yang diberikan oleh JNE kurang baik. Seperti kurang ramah terhadap pelanggan dan juga ruang tunggu yang kurang nyaman dan tidak tersedianya banyak kursi sehingga pelanggan sering berdiri untuk menunggu barang yang akan diambil. Mungkin salah satu penyebabnya karena kurangnya SDM sehingga harus menunggu lama terutama di bagian costumer service. Selain itu juga, tidak adanya fasilitas seperti TV dan koran yang dapat menajadi hiburan pada saat menunggu. Seharusnya dalam suatu perusahaan jasa, yang dimana yang dijual adalah jasanya maka pelayanan yang diberikan harus memuaskan pelanggan, harus ramah dan memperlakukan pelanggan dengan baik [2] 
Pelayanan merupakan menolong menyediakan segala apa yang diperlukan orang lain seperti tamu atau pembeli. (Kamus Umum Bahasa Indonesia 2018). Pelayanan yang baik adalah keadaan dimana si penerima dan pemberi layanan sama-sama merasa diuntungkan. Dimensi kualitas pada industri jasa antara lain: (1) communication, yaitu komunikasi atau hubungan antara penerima jasa dengan pemberi jasa. (2) credibility, yaitu kepercayaan pihak penerima jasa terhadap pemberi jasa. (3) security, yaitu keamanan terhadap jasa yang ditawarkan. (4) knowing the customer, yaitu pengertian dari pihak pemberi jasa pada penerima jasa atau pemahaman pemberi jasa terhadap kebutuhan dan harapan pemakai jasa. (5) tangibles, yaitu bahwa dalam memberikan pelayanan kepada pelanggan harus dapat diukur atau dibuat standarnya. (6) reliability, yaitu konsistensi kerja pemberi jasa dan kemampuan pemberi jasa dalam memenuhi janji para penerima jasa. (7) responsiveness, yaitu tanggapan pemberi jasa tehadap kebutuhan dan harapan penerima jasa. (8) competence, yaitu kemampuan atau keterampilan pemberi jasa yang dibutuhkan setiap orang dalam perusahaan untuk memberikan jasanya kepada penerima jasa. (9) access, yaitu kemudahan pemberi jasa untuk dihubungi oleh pihak pelanggan atau penerima jasa. (10) courtesy, yaitu kesopanan, respek, perhatian, dan kesamaan dalam hubungan personil [5]

Teori yang populer menyatakan bahwa penyedia jasa harus mampu memuaskan pelanggan dengan memberikan kualitas pelayanan. Perusahaan jasa yang sukses adalah perusahaan yang mampu mencapai tingkat kualitas secara konsisten. Kualitas pelayanan yang baik ialah pelayanan yang mengikuti SOP yang sudah dibuat oleh suatu perusahaan. JNE Tanjung Selor pun memiliki SOP tetapi masih ada yang belum diterapkan sesuai dengan SOP yang ada [4]

Table 1 TAHAP 2 (Ketika pelanggan mengirim atau melaksanakan transaksi)

\begin{tabular}{|l|}
\hline Langkah: \\
\hline $\begin{array}{l}\text { Memastikan tampilan bangunan yang standard dan memberikan keyakinan pada } \\
\text { pelanggan }\end{array}$ \\
\hline $\begin{array}{l}\text { Memastikan kemudahan akses pelanggan untuk menuju tempat transaksi } \\
\text { (petunjuk dll) }\end{array}$ \\
\hline Memastikan pelanggan mudah dan aman dalam memarkir kendaraan \\
\hline cccc \\
\hline $\begin{array}{l}\text { Melayani transaksi dengan standar pelayanan transaksi JNE (dari greeting sampai } \\
\text { akhir) }\end{array}$ \\
\hline $\begin{array}{l}\text { Melakukan transaksi sesuai SOP } \\
\text { tidak baik/rusak }\end{array}$ \\
\hline $\begin{array}{l}\text { Sediakan layanan lebih (bungkus kiriman, pastikan alat bungkus tersedia baik, dan } \\
\text { petugas membantu membungkuskan jika perlu, penyediaan pembungkus } \\
\text { (bayar/gratis), form alamat, dll) }\end{array}$ \\
\hline $\begin{array}{l}\text { Memastikan performa petugas cash sales counter dan staf kantor yang baik dan } \\
\text { mengesankan }\end{array}$ \\
\hline
\end{tabular}


Memastikan layanan pickup sesuai SOP dan sesuai kebutuhan pelanggan (ketepatan waktu)

Menyediakan payung JNE di counter untuk kemudian staf Counter membantu pelanggan yang kehujanan ketika akan mengirim atau setelah mengirim, untuk memberikan pengalaman pelanggan yang mengesankan

Sumber : SOP JNE

Dari data diatas, terutama di poin ke empat "Memastikan kenyamanan pelanggan dalam mengantri (kursi, kartu antrian, hiburan televisi/radio/music,permen, minuman, pengatur udara, bahan bacaan, dll)". Sedangkan di JNE Tanjung Selor hal tersebut belum diterapkan dengan baik. Kurangnya kursi yang tersedia menyebabkan banyak pelanggan yang berdiri, selain itu juga tidak terdapat tv, permen, dan yang sesuai dengan SOP yang sudah ada yang menyebabkan pelanggan bosan untuk menunggu.

Dijelaskan lebih lanjut, bahwa beberapa hasil penelitian empiris banyak menudukung fenomena tersebut keunggulan kompetensi bukan menjadi jaminan untuk menghasilkan kinerja organisasi yang hebat. Tetapi antara kompetensi pegawai dan kinerja organisasi, harus dibangun sumber pemberdayaan yang bisa menghasilkan inovasi keunggulan bersaing, barulah mampu mendorong peningkatan kinerja organisasi. Pada prinsipnya, keunggulan bersaing bisa diciptakan secara tepat jika pemetaan antara kompetensi pegawai dan kinerja organisasi bisa dipadukan menjadi sebuah hubungan yang sinergis.

Dalam pemikiran sederhana, perusahaan belum tentu sukses sekalipun didalamnya dipenuhi orang pandai. Pandai memang menjadi prasyarat jika perusahaan ingin sukses. Tetapi pandai saja belum cukup, kalau kepandaiannya tidak digunakan untuk menghasilkan sebuah kreatifitas dan inovasi. Jika kinerja perusahaan bisa meningkat karena dipengaruhi oleh aktivitas inovasi untuk menciptakan keunggulan bersaing,berati langkah selanjut nya harus dilakukan adalah membuat program-program inovasi untuk menciptakan keunggulan bersaing. Setiap perusahaan tentu akan berbeda-beda penyusunan programnya. Banyak hal yang harus disesuaikan, misalnya jenis usaha, produk dan jasa yang dikembangkan, segmen pasar, dan lain-lain.

Menurut kami, pesaing adalah lawan berpikir untuk menajadikan perusahaan lebih baik lagi dalam berbagai hal, misalnya mutu pelayanan, tempat yang nyaman, harga yang ditawarkan, dan lain-lain. Disisi lain pesaing dapat membawa keuntungan dan juga membawa kerugian. Apabila pesaing kinerjanya lebih baik dari perusahaan kita maka akan menimbulkan kerugian, pun sebaliknya apabila kinerja perusahaan dibawah perusahaan kita maka akan menimbulkan keuntungan. Namun dengan adanya pesaing maka akan menambah semangat kita untuk membuat inovasi usaha yang kita jalankan agar mampu bersaing dengan kompetitor lain. 


\section{BAB III \\ PENUTUP}

\section{A. Solusi kreatif dan inovatif}

Berdasarkan penjelasan di atas mengenai permasalahan yang terjadi di JNE Tanjung Selor, baik yang dirasakan pihak eksternal maupun internal perusahaan, maka kami merumuskan beberapa solusi yaitu:

1. Peningkatan pelayanan di JNE Tanjung Selor. Seperti yang kita ketahui bahwa pelayanan merupakan suatu hal yang sangat penting untuk dapat mempertahankan loyalitas konsumen. Peningkatan pelayanan JNE Tanjung Selor dapat dilakukan dengan 2 (dua) hal yaitu : 1) Memberikan nomor antrian bagi konsumen, 2) Penambahan fasilitas ruang tunggu kantor JNE. Pemberian nomor antrian belum diterapkan di JNE Tanjung Selor sehingga banyak konsumen yang seenaknya sendiri untuk mengambil antrian orang lain. Dengan pemberian nomor antrian diharapkan akan terjadi ketertiban dan kenyamanan pelayanan di JNE Tanjung Selor. Penambahan fasilitas ruang tunggu dalam hal ini adalah penambahan dan penyusunan kursi di ruang tunggu, hal ini ditujukan untuk meningkatkan kenyamanan konsumen ketika berada didalam ruang tunggu kantor JNE. Ketersediaan kursi menjadi penting karena selama ini masih ditemui konsumen yang berdiri ketika hendak menggunakan layanan di JNE. Selain itu juga, dapat diberikan hiburan kepada konsumen selama menunggu, seperti tersedianya televisi maupun bahan bacaan seperti koran atau majalah. Pada dasarnya hal ini sudah ditegaskan pada SOP JNE yaitu "memastikan kenyamanan pelanggan dalam mengantri (kursi, kartu antrian, hiburan televisi/radio/music, permen, minuman, pengatur udara, bahan bacaan, dll)".

2. Pengembangan aplikasi JNE dengan menggunakan fitur peta (maps) agar rute perjalanan barang dapat dilihat dengan detail dan real time. Aplikasi ini dapat digunakan untuk komunikasi oleh dua pihak yaitu pengirim dan penerima agar tidak terjadi miss komunikasi yang menyebabkan keterlambatan barang yang sampai ke penerima. Setelah barang sampai ke kantor JNE, lalu untuk pengiriman barang ke rumah konsumen, kurir dan juga penerima dapat sama-sama menggunakan aplikasi ini lagi agar tidak terjadi kesalahan pengiriman dikarenakan alamat yang tidak jelas. Untuk dapat melihat rute perjalanan dengan aplikasi ini maka harus memasukan nomor resi atau barcode pengiriman pada barang tersebut. Untuk kurir yang akan mengirim barang tersebut juga harus memasukan nomor resi atau barcode untuk mengetahui alamat penerima. Sehingga tidak terjadi lagi pencarian alamat penerima yang tidak jelas, sehingga dapat mengefesiensikan waktu pengiriman.

3. 3. Penerapan JNE Loyalty Card (JLC) di Tanjung Selor. Program JNE Loyalty Card (JLC) merupakan program keanggotaan yang ditujukan kepada pelanggan JNE. Untuk mendapatkan JLC, konsumen dapat 
mendaftarkan diri di Kantor JNE terdekat dan JLC dapat digunakan di Seluruh Indonesia. JLC ini memiliki nomor ID pelanggan yang kegunaannya untuk merekam jejak transaksi konsumen. Bagi pemegang JLC diberikan beberapa keuntungan seperti kecepatan layanan, potongan harga pada saat periode promo, dan hadiah undian yang sangat menarik. Pemegang JLC akan mendapat reward satu poin untuk setiap transaksi senilai 25 ribu rupiah di JNE. Poin tersebut bisa ditukar dengan hadiah menarik atau diskon khusus di banyak merchant. Tambahan kami terhadap JLC ini adalah adanya perbedaan tingkatan berdasarkan poin yang terkumpul. Misalnya untuk poin terendah masuk di JLC silver, ditingkat tengah JLC golden, dan untuk tingkatan poin semakin banyak akan mendapat JLC diamond. Dan keuntungan yang diberikan pada saat ada perbedaan tingkatan adalah semakin tinggi poin yang ada maka pada saat melakukan transaksi dipermudah, dan juga bisa mendapatkan potongan harga yang sesuai dengan jenis kartu yang kita milik. Dengan begitu maka konsumen akan berlomba-lomba agar poin yang terkumpul banyak, sehingga mendapatkan potongan harga serta pelayanan yang memuaskan. Dan juga, JNE Tanjung Selor harus menerapkan pemberian reward kepada konsumen setiap periode. Misalnya pengundian hadiah, atau pemberian hadiah kepada pelanggan setia JNE pada periode tersebut.

\section{Bibliography}

[1] BBCC, Booklet Borneo Case Competition, Tarakan: Fakultas EKonomi Jurusan Manajemen Universitas Borneo, 2019.

[2] R. Hartono, Interviewee, [Interview]. 12 Januari 2019.

[3] KKBI, "KBBI.we.id," 23 Maret 2018. [Online]. Available: http://www.KBBI.we.id. [Accessed 12 Januari 2019].

[4] J. E. Panjaitan, "PENGARUH KUALITAS PELAYANAN TERHADAP KEPUASAN," DeReMa Jurnal Manajemen, vol. 11, no. 2, 2016.

[5] A. G. David, Managing quality: The strategic and competitive edge, Simon and Schuster, 1988.

[6] C. Indonesia, "https://www.cnnindonesia.com/," CNN Indonesia, 23101990. [Online]. Available: https://www.cnnindonesia.com/ekonomi/20190113164934-92360483/maskapai-tuding-rupiah-penyebab-kenaikan-harga-tiket-pesawat. [Accessed 1201 2019]. 